\title{
Optimized Neural Network Prediction Model of Shape Memory Alloy and Its Application for Structural Vibration Control
}

\author{
Meng Zhan ${ }^{1, * \mathbb{C}}$, Junsheng Liu ${ }^{2}$, Deli Wang ${ }^{3}$, Xiuyun Chen ${ }^{1}$, Lizhen Zhang ${ }^{1}$ and Sheliang Wang ${ }^{4}$ \\ 1 College of Construction Engineering, HuangHuai University, No. 76 Kaiyuan RD., Zhumadian 463000, China; \\ Cxy0396@126.com (X.C.); zhenzhen_5255@sina.com (L.Z.) \\ 2 Shaanxi Institute of Building Science, No. 272 Huancheng RD., Xi'an 710082, China; jsliu1973@163.com \\ 3 Taizhou Urban and Rural Planning and Design Institute, No. 465 Shifu RD., Taizhou 318000, China; \\ wangdeli2012@sina.com \\ 4 College of Civil Engineering, Xi'an University of Architecture and Technology, No. 13 Yanta RD., \\ Xi'an 710055, China; sheliangw@163.com \\ * Correspondence: zhanyi313@163.com
}

\section{check for} updates

Citation: Zhan, M.; Liu, J.; Wang, D.; Chen, X.; Zhang, L.; Wang, S. Optimized Neural Network Prediction Model of Shape Memory Alloy and Its Application for Structural Vibration Control. Materials 2021, 14, 6593. https://doi.org/10.3390/ ma14216593

Academic Editors: Salvatore Saputo and Radim Kocich

Received: 13 September 2021

Accepted: 27 October 2021

Published: 2 November 2021

Publisher's Note: MDPI stays neutral with regard to jurisdictional claims in published maps and institutional affiliations.

Copyright: (c) 2021 by the authors. Licensee MDPI, Basel, Switzerland. This article is an open access article distributed under the terms and conditions of the Creative Commons Attribution (CC BY) license (https:// creativecommons.org/licenses/by/ $4.0 /)$.

\begin{abstract}
The traditional mathematical model of shape memory alloy (SMA) is complicated and difficult to program in numerical analysis. The artificial neural network is a nonlinear modeling method which does not depend on the mathematical model and avoids the inevitable error in the traditional modeling method. In this paper, an optimized neural network prediction model of shape memory alloy and its application for structural vibration control are discussed. The superelastic properties of austenitic SMA wires were tested by experiments. The material property test data were taken as the training samples of the BP neural network, and a prediction model optimized by the genetic algorithm was established. By using the improved genetic algorithm, the position and quantity of the SMA wires were optimized in a three-storey spatial structure, and the dynamic response analysis of the optimal arrangement was carried out. The results show that, compared with the unoptimized neural network prediction model of SMA, the optimized prediction model is in better agreement with the test curve and has higher stability, it can well reflect the effect of loading rate on the superelastic properties of SMA, and is a high precision rate-dependent dynamic prediction model. Moreover, the BP network constitutive model is simple to use and convenient for dynamic simulation analysis of an SMA passive control structure. The controlled structure with optimized SMA wires can inhibit the structural seismic responses more effectively. However, it is not the case that the more SMA wires, the better the shock absorption effect. When SMA wires exceed a certain number, the vibration reduction effect gradually decreases. Therefore, the seismic effect can be reduced economically and effectively only when the number and location of SMA wires are properly configured. When four SMA wires are arranged, the acceptable shock absorption effect is obtained, and the sum of the structural storey drift can be reduced by $44.51 \%$.
\end{abstract}

Keywords: SMA; prediction model; BP neural network; genetic algorithm; seismic response

\section{Introduction}

Shape memory alloy (SMA) is a novel functional material, which not only has two unique properties of shape memory and super elasticity, but also has the advantages of high damping, fatigue, and corrosion resistance [1-3]. Therefore, SMA has been widely used in the field of civil engineering for reinforcement and vibration control [4-6]. Dehghani and Aslani developed hooked-end pseudoelastic shape memory alloy fibres (PSMAF) which can provide re-centring and crack-closing behaviour in cementitious composites [7]. Rezapour et al. investigated the effects of SMA post-tensioning reinforcements on originally unreinforced masonry walls using Abaqus soft [8]. Siddiquee et al. evaluated the seismic performance of concrete frame buildings reinforced with superelastic SMA rebar in terms of the collapse margin ratio, and the results are compared with that of a reinforced concrete 
structure with regular steel rebar only [9]. Schranz et al. studied the effectiveness of two different prestressed strengthening methods for flexural behavior of concrete members using ribbed Fe-SMA bars [10]. Peng et al. proposed a shape memory alloy cable-double friction pendulum bearing which combines a double friction pendulum bearing with superelastic SMA cables [11]. Based on the pseudoelasticity of SMA and the electrodeformation of piezoelectric transition ceramic, Zhan et al. designed a novel SMA/PZT composite control device and investigated its energy dissipation performance and neural network constitutive model [12]. In addition, some researchers discussed the control of shape memory alloy actuator using PID controller and pulse width modulation [13-16].

The constitutive model of SMA material is the basis of theoretical analysis and experimental study for properties of SMA $[17,18]$. A series of constitutive models of SMA have been established based on material experiments. Falk established a theoretical constitutive model of a single crystal based on Landau's theory, but it only applies to single crystal and only considers the shearing motion of crystal [19]. Abeyartane and Knowle proposed a onedimensional constitutive model of SMA material by using the thermodynamic bar theory and combining the Helmholzt free energy principle and the expression of thermodynamic relation, but this model did not consider the redirection of stress-induced martensite variation under non-proportional load [20]. Boyd and Lagoudas presented a meso-mechanical constitutive model based on meso-mechanics and thermodynamics, but this model is too complex to be applied in engineering [21]. Based on the constitutive relationship between thermodynamics and kinetics, Brinson proposed a phenomenological constitutive model with the characteristics of plasticity theory, which is the most widely used constitutive model of SMA [22]. Liu et al. explored a macroscopic phenomenological constitutive model involving strain amplitude and loading rate by introducing an internal variable evolution equation, considering the difference of characteristic parameters during the positive/reverse transformation of martensite and the hardening properties of martensite under large strain amplitudes [23]. Based on the Landau theory of phase transitions, Du et al. proposed a differential model to describe the hysteresis of magnetic shape memory alloys caused by magnetic field induced martensite reorientation [24]. However, for shape memory alloy, there are many factors affecting its constitutive model, so it is impossible to establish an accurate mathematical model to express the influence of all various factors on it, and it can only be simplified and approximated artificially. The artificial neural network does not need to achieve the precise constitutive relation of the material, but only needs to consider the influencing factors and expected objectives, and it avoids the inevitable error in the traditional modeling method and provides a new way to establish the accurate SMA constitutive model. Lee and Lee used a multi-layer perceptron neural network to forecast the resilience of SMA [25]. Ren et al. used a radial basis function network to forecast the hysteresis behavior of SMA at the same strain amplitude with the number of cycles, loading information, and strain value as the input of neurons [26]. However, the change of initial weight/threshold of neurons has a great influence on the prediction results of the artificial neural network, so the initial weight/threshold should be optimized in the neural network to improve the accuracy and stability.

The damping effect of the SMA damper on an engineering structure is mainly determined by its own performance, installation position, and layout number $[27,28]$. Even if its damping force is large and the shock absorption effect is good, the ideal damping effect may not be achieved if the installation position and number are inappropriate [29-31]. Therefore, in order to achieve the efficiency and economy of the SMA control system, it is necessary to optimize the installation position and quantity of SMA wires in the engineering application. By idealizing the hysteretic curve of SMA damper and the transient tangent stiffness matrix of structure, Mulay and Shmerling presented a simplified nonlinear equation model to design SMA dampers in three-dimensional asymmetric plane structures [32]. Pang et al. proposed a novel seismic risk-based optimization design method of SMA restrained sliding bearings in highway bridges suffered from near-fault ground motions via the particle swarm optimization [33]. Zhan et al. discussed the optimal arrangement of SMA piezo- 
electric composite dampers in a space truss structure using the adaptive immune memory cloning algorithm with the performance indicator based on the modal controllable degree as antigen-antibody affinity function [34].

This paper explored a novel SMA prediction model considering loading rate and loading history via a back-propagation (BP) neural network optimized by the genetic algorithm (GA). SMA wires were selected to control the dynamics response of a threestorey spatial structure, and the application of artificial neural network to SMA constitutive model and the damping effect of SMA wires on the seismic response of spatial structure are discussed. Firstly, the sum of lateral inter-story displacement is taken as the control objective, the optimization of the number and position of SMA wires is carried out by applying the improved genetic algorithm. Then, the Newmark- $\beta$ method is employed to accomplish the seismic response control analysis of the spatial structure with an optimal allocation of SMA wires via MATLAB soft.

\section{SMA Wire Mechanical Performance Test}

\subsection{Test Loading Scheme}

The chemical composition of the austenitic SMA wire used in the test is Ti-51\%atNi $[35,36]$ with diameters $0.5,0.8,1.0$, and $1.2 \mathrm{~mm}$. Phase transition temperature: Martensite finish temperature $M_{\mathrm{f}}$ is $-42{ }^{\circ} \mathrm{C}$; Martensite start temperature $M_{\mathrm{s}}$ is $-38{ }^{\circ} \mathrm{C}$; Austenite start temperature $A_{\mathrm{s}}$ is $-6{ }^{\circ} \mathrm{C}$; Austenite finish temperature $A_{\mathrm{f}}$ is $-2{ }^{\circ} \mathrm{C}$. Taiwan Hongda HT-2402 computer servo-controlled material testing machine is used in Material Science Laboratory of Xi'an University of Technology. The axial force is measured by the force sensor that comes with the testing machine, and the axial deformation is measured by the displacement extensometer. The gauge length is $33.5 \mathrm{~mm}$, and all data are automatically collected by computer.

This test mainly considers the influence of the number of loading cycles, strain amplitude, loading rate, and material diameter on the stress-strain curve, energy dissipation capacity, equivalent damping ratio, and equivalent secant modulus of austenitic SMA wire. In this experiment, the loading rate was $10 \mathrm{~mm} / \mathrm{min}, 30 \mathrm{~mm} / \mathrm{min}, 60 \mathrm{~m} / \mathrm{min}, 90 \mathrm{~mm} / \mathrm{min}$, and the strain amplitude was $3 \%, 6 \%$, and $8 \%$. To ensure the accuracy of the test, a pretension of 10 30 MPa is applied to the SMA wire before each working condition starts to work so that the SMA wire can be straightened and tightened. To eliminate the influence of the test piece length on SMA, the length of the test piece used is $300 \mathrm{~mm}$ with an effective length of $100 \mathrm{~mm}$. In each cycle, only when the SMA wire strain reaches the amplitude strain, loading stops, and when the axial force of the SMA wire was less than $5 \mathrm{~N}$, unloading stops. Loading cycle was 30 cycles in each working condition.

\subsection{Test Results and Analysis}

The stress of four points $\left(\sigma_{a}, \sigma_{b}, \sigma_{c}, \sigma_{d}\right)$ is used to replace the critical stress of SMA transformation, as shown in Figure 1. The starting point of the stress-strain curve platform of the loading section is taken as point a. The point where the slope of the loading section curve is significantly increased after the loading platform is taken as point $b$. The point where the stress-strain drops start to deviate from the linear relation is taken as point c. The point where the stress and strain begin to decrease at the end is taken as point $d$. Substituting the above-mentioned points for the phase transition critical point of austenite SMA, although there is a certain error between the characteristic point stress and the true phase transition stress of SMA, the phase transition process of SMA can still be reflected. 


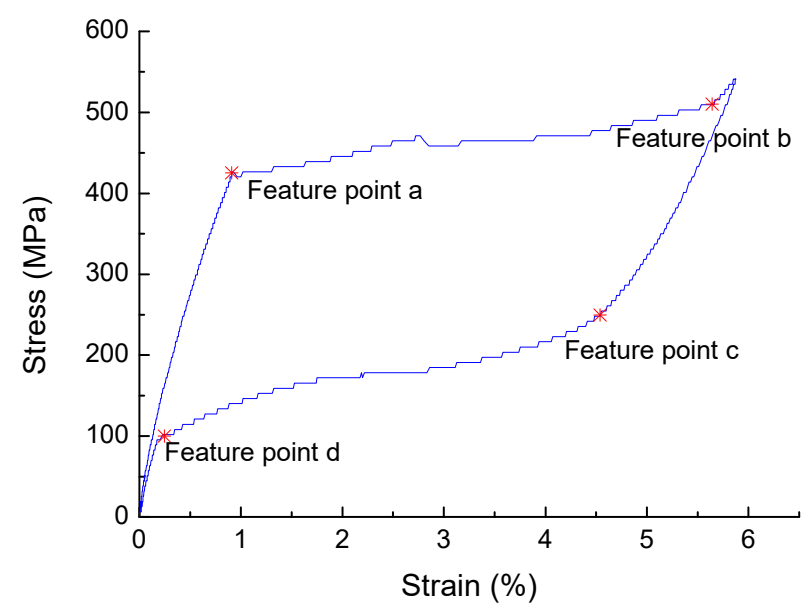

Figure 1. Characteristic points of austenite SMA constitutive curve.

The mechanical performance indicators are defined as follows: $\Delta W$ represents the energy consumption value of the SMA wire in a single cycle, that is, the graphic area enclosed by the stress-strain curve; $K_{\mathrm{s}}$ represents the equivalent secant stiffness of a single cycle; $\delta$ represents the equivalent damping ratio of a single cycle.

$$
\begin{gathered}
K_{\mathrm{s}}=\frac{\sigma_{\max }-\sigma_{\min }}{\varepsilon_{\max }-\varepsilon_{\min }} \\
\delta=\frac{\Delta W}{2 \pi K_{\mathrm{s}} \varepsilon^{2}}
\end{gathered}
$$

where $\sigma_{\max }\left(\varepsilon_{\max }\right)$ and $\sigma_{\min }\left(\varepsilon_{\min }\right)$ respectively represent the maximum stress (strain) and minimum stress (strain) of each cycle, and $\varepsilon$ is the amplitude strain.

According to the experimental results, the effects of cyclic loading, strain amplitude, loading rate and material diameter on the mechanical properties of austenitic SMA wire are analyzed.

(1) The effect of cyclic loading on the mechanical properties of superelasticity. The stressstrain curve with a diameter of $1.0 \mathrm{~mm}$, a loading rate of $10 \mathrm{~mm} / \mathrm{min}$, and a strain amplitude of 3\% is shown in Figure 2, and the parameters are shown in Table 1. It can be seen that, with the increase of the number of cycles, the cumulative residual deformation of the austenitic SMA wire gradually increases, but the residual deformation of the single cycle gradually becomes smaller, and stabilizes after 15 cycles, and the residual strain is zero. With the increase in the number of cycles of loading, the performance of austenitic SMA wire gradually stabilizes, the stress-strain curve gradually becomes smooth, the energy dissipation capacity and equivalent damping ratio of the SMA wire gradually decrease, and the equivalent secant stiffness slightly decreased, but stabilized after 15 loading/unloading cycles. The number of cycles has a great influence on the mechanical properties of austenitic SMA wire. In actual engineering applications, in order to obtain stable superelastic properties, the SMA wire must be cyclically loaded in advance, and it usually takes about 20 cycles. 


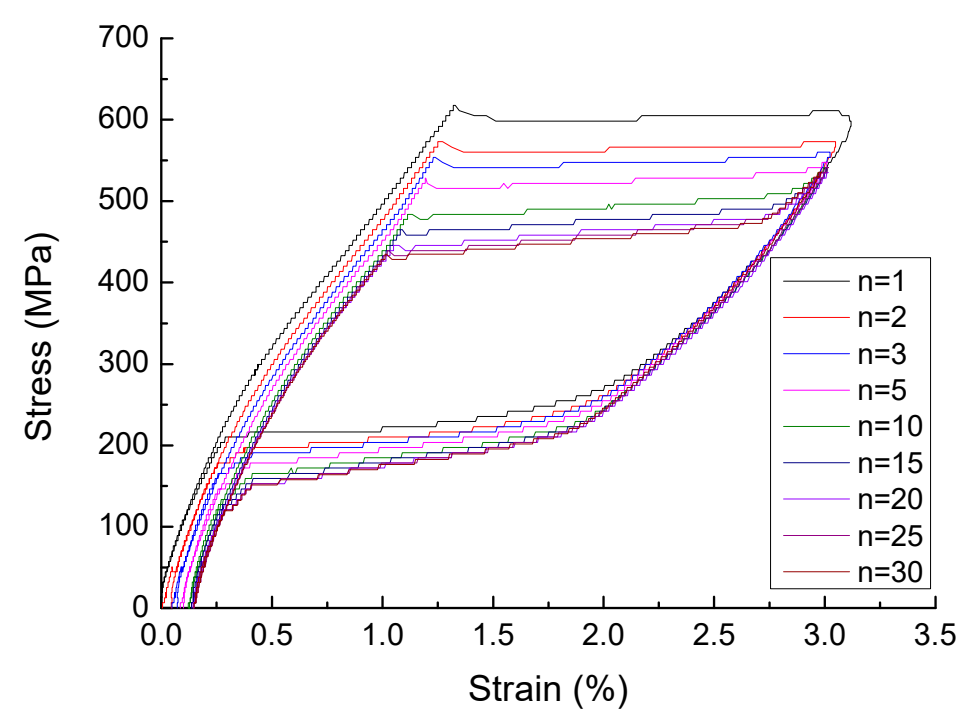

Figure 2. Stress-strain curve of austenite SMA wire with different cycles.

Table 1. Mechanical properties of SMA wires with different cycles.

\begin{tabular}{|c|c|c|c|c|c|c|c|}
\hline Cycles & $\begin{array}{c}\sigma_{a} \\
(\mathrm{MPa})\end{array}$ & $\begin{array}{c}\sigma_{b} \\
(\mathrm{MPa})\end{array}$ & $\begin{array}{c}\sigma_{c} \\
(\mathrm{MPa})\end{array}$ & $\begin{array}{c}\sigma_{d} \\
(\mathrm{MPa})\end{array}$ & $\begin{array}{c}\Delta W \\
\left(\mathrm{MJ} \cdot \mathrm{m}^{-3}\right)\end{array}$ & $\begin{array}{c}\zeta_{a} \\
(\%)\end{array}$ & $\begin{array}{c}K_{s} \\
(\mathrm{GPa})\end{array}$ \\
\hline 1 & 604.79 & 604.79 & 273.75 & 178.25 & 6.84 & 6.11 & 19.78 \\
\hline 2 & 560.23 & 572.96 & 254.65 & 171.89 & 6.19 & 5.81 & 18.84 \\
\hline 3 & 541.13 & 560.23 & 241.92 & 171.89 & 5.80 & 5.44 & 18.82 \\
\hline 5 & 515.66 & 541.13 & 241.92 & 165.52 & 5.48 & 5.18 & 18.72 \\
\hline 10 & 483.83 & 509.30 & 222.82 & 159.15 & 5.04 & 4.76 & 18.71 \\
\hline 15 & 464.73 & 496.56 & 222.82 & 159.15 & 4.77 & 4.48 & 18.81 \\
\hline 20 & 439.27 & 483.83 & 216.45 & 152.79 & 4.60 & 4.37 & 18.62 \\
\hline 25 & 432.90 & 477.46 & 216.45 & 152.79 & 4.46 & 4.18 & 18.88 \\
\hline 30 & 432.90 & 477.46 & 216.45 & 152.79 & 4.44 & 4.16 & 18.85 \\
\hline
\end{tabular}

(2) The effect of strain amplitude on the mechanical properties of superelasticity. A stress-strain curve with a diameter of $1.0 \mathrm{~mm}$, a loading rate of $10 \mathrm{~mm} / \mathrm{min}$, and a strain amplitude of 3\% is shown in Figure 3, and the parameters are shown in Table 2. As the strain amplitude of SMA wire increases, the cumulative residual deformation gradually increases. When the strain amplitude is small, the austenitic SMA wire is basically in the elastic stage, and the elastic modulus is approximately $450 \mathrm{MPa}$ after stabilization. When the strain amplitude exceeds 1\%, the SMA wire will undergo martensitic transformation and austenite transformation, showing super-elastic performance, and the greater the strain amplitude, the better its super-elastic performance, and the greater the energy dissipation capacity. The strain amplitude is the most significant factor affecting the energy dissipation capacity of SMA wires. When the strain amplitude increases from $3 \%$ to $8 \%$, the single-turn energy consumption of the SMA wire increases from $4.46 \mathrm{MJ} \cdot \mathrm{m}^{-3}$ to $20.76 \mathrm{MJ} \cdot \mathrm{m}^{-3}$, which increases the energy consumption by 3.65 times. As the strain amplitude increases, the damping ratio gradually increases, the equivalent secant stiffness gradually decreases, and the energy consumption capacity continues to increase. 


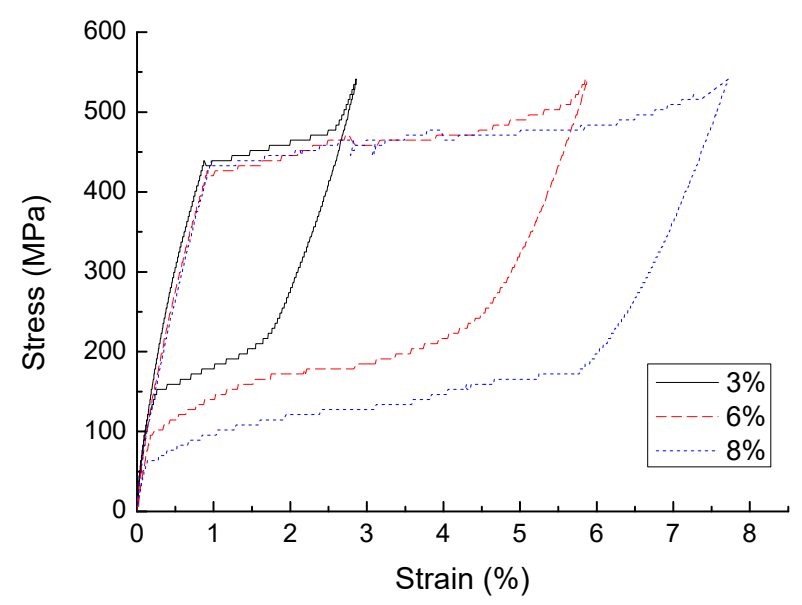

Figure 3. Stress-strain curve of austenite SMA wire with different strain amplitudes.

Table 2. Mechanical properties of SMA wires with different strain amplitudes.

\begin{tabular}{cccccccc}
\hline Strain Amplitudes & $\begin{array}{c}\sigma_{\boldsymbol{a}} \\
\mathbf{M P a}\end{array}$ & $\begin{array}{c}\sigma_{\boldsymbol{b}} \\
\mathbf{( M P a})\end{array}$ & $\begin{array}{c}\sigma_{\boldsymbol{c}} \\
\mathbf{( M P a})\end{array}$ & $\begin{array}{c}\sigma_{\boldsymbol{d}} \\
\mathbf{( M P a})\end{array}$ & $\begin{array}{c}\Delta W \\
\mathbf{( M J . m}\end{array}$ & $\begin{array}{c}\zeta_{\boldsymbol{a}} \\
(\mathbf{\%})\end{array}$ & $\begin{array}{c}\boldsymbol{K}_{\boldsymbol{s}} \\
(\mathbf{G P a})\end{array}$ \\
\hline $3 \%$ & 432.90 & 496.56 & 260.65 & 120.96 & 4.46 & 4.18 & 18.88 \\
$6 \%$ & 420.17 & 509.30 & 254.65 & 101.86 & 12.70 & 6.09 & 9.21 \\
$8 \%$ & 432.90 & 515.66 & 254.65 & 70.03 & 20.76 & 6.60 & 7.81 \\
\hline
\end{tabular}

(3) The effect of loading rate on the mechanical properties of superelasticity. The stressstrain curve of the 30th cycle with a diameter of $1.0 \mathrm{~mm}$, and a strain amplitude of $6 \%$ is shown in Figure 4, and the parameters are shown in Table 3. As the loading rate increases, the single-cycle energy consumption of the austenitic SMA wire gradually decreases, and the shape of the stress-strain curve changes significantly. In the phase of unloading, the initial stress of the change increases significantly. The stress-strain shape gradually transitions from a rectangle and a diamond to a trapezoid and a narrower triangle. The area enclosed by the hysteresis curve gradually decreases. The equivalent damping ratio and equivalent stiffness generally show a decreasing trend and energy consumption gradually decreases. This is mainly because the heat generated during the loading process of the SMA wire causes the temperature rise of the SMA specimen, which reduces its own energy consumption.

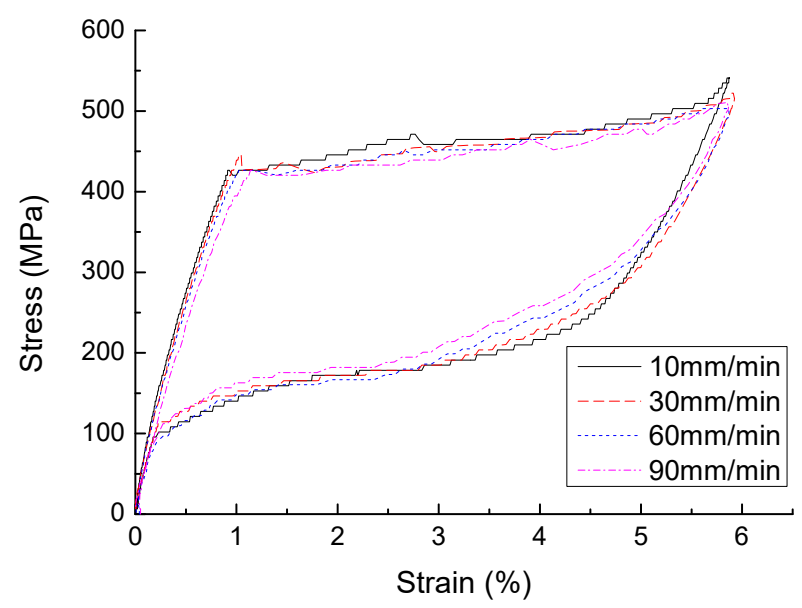

Figure 4. Stress-strain curve of austenite SMA wire with different loading rates. 
Table 3. Mechanical properties of SMA wires with different loading rates.

\begin{tabular}{|c|c|c|c|c|c|c|c|}
\hline Loading Rates & $\begin{array}{c}\sigma_{a} \\
(\mathbf{M P a})\end{array}$ & $\begin{array}{c}\sigma_{b} \\
(\mathrm{MPa})\end{array}$ & $\begin{array}{c}\sigma_{c} \\
(\mathrm{MPa})\end{array}$ & $\begin{array}{c}\sigma_{d} \\
(\mathrm{MPa})\end{array}$ & $\begin{array}{c}\Delta W \\
\left(\mathrm{MJ}^{\prime} \mathrm{m}^{-3}\right)\end{array}$ & $\begin{array}{c}\zeta_{a} \\
(\%)\end{array}$ & $\begin{array}{c}K_{s} \\
(\mathrm{GPa})\end{array}$ \\
\hline $10 \mathrm{~mm} / \mathrm{min}$ & 420.17 & 509.30 & 254.65 & 101.86 & 12.70 & 6.09 & 9.21 \\
\hline $30 \mathrm{~mm} / \mathrm{min}$ & 426.54 & 515.36 & 280.11 & 107.59 & 12.31 & 6.25 & 8.70 \\
\hline $60 \mathrm{~mm} / \mathrm{min}$ & 420.17 & 502.93 & 326.04 & 109.86 & 11.93 & 6.15 & 8.58 \\
\hline $90 \mathrm{~mm} / \mathrm{min}$ & 420.17 & 502.93 & 331.94 & 118.23 & 10.52 & 5.34 & 8.71 \\
\hline
\end{tabular}

(4) The effect of diameters on the mechanical properties of superelasticity. The stressstrain curve of the 30th cycle with a loading ratio of $90 \mathrm{~mm}$, and a strain amplitude of $6 \%$ is shown in Figure 5, and the parameters are shown in Table 4. As the diameter of the material increases, the stress-strain curve of the SMA wire tends to be smooth, but the number of cycles required to reach stability increases, and the cumulative residual deformation presents a gradually increasing trend. The stress of each characteristic point of SMA wire decreases with the increase of the material diameter. As the diameter of the material increases, the energy dissipation capacity and equivalent damping ratio show a significant decrease. This is mainly due to the increase in the diameter of the material, and the heat generated during the loading process cannot be dissipated in time, causing the specimen temperature to increase, which reduces the energy consumption of SMA wire. The equivalent stiffness is less affected by the diameter, and the change is not obvious. Therefore, in engineering applications, SMA wires with appropriate diameters should be selected for the passive control of seismic response.

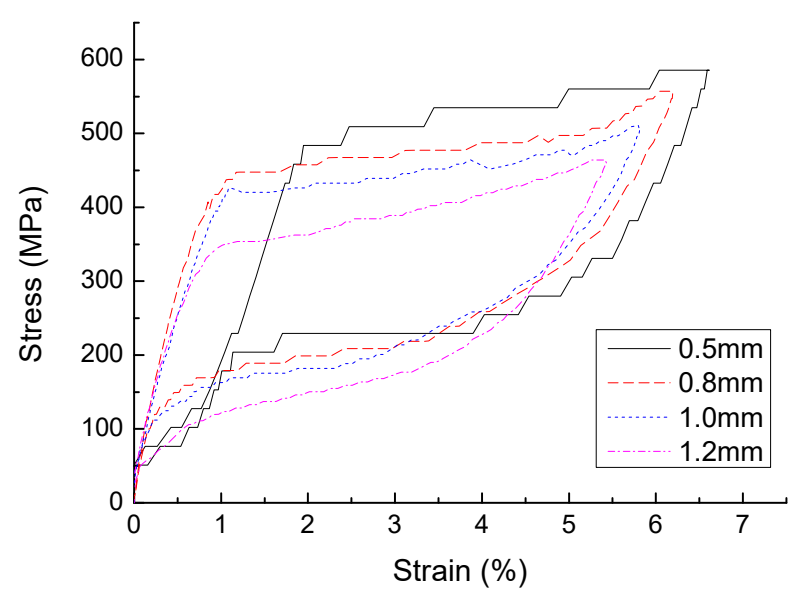

Figure 5. Stress-strain curve of austenite SMA wire with different diameters.

Table 4. Mechanical properties of SMA wires with different diameters.

\begin{tabular}{|c|c|c|c|c|c|c|c|}
\hline Diameters & $\begin{array}{c}\sigma_{a} \\
(\mathrm{MPa})\end{array}$ & $\begin{array}{c}\sigma_{b} \\
(\mathrm{MPa})\end{array}$ & $\begin{array}{c}\sigma_{c} \\
(\mathrm{MPa})\end{array}$ & $\begin{array}{c}\sigma_{d} \\
(\mathrm{MPa})\end{array}$ & $\begin{array}{c}\Delta W \\
\left(\mathrm{MJ} \cdot \mathrm{m}^{-3}\right)\end{array}$ & $\begin{array}{c}\zeta_{a} \\
(\%)\end{array}$ & $\begin{array}{c}K_{s} \\
(\mathrm{GPa})\end{array}$ \\
\hline $0.5 \mathrm{~mm}$ & 483.83 & 585.69 & 331.04 & 203.72 & 12.43 & 6.49 & 8.47 \\
\hline $0.8 \mathrm{~mm}$ & 447.62 & 527.20 & 358.10 & 139.26 & 12.22 & 6.01 & 8.99 \\
\hline $1.0 \mathrm{~mm}$ & 420.17 & 502.93 & 331.94 & 118.23 & 10.52 & 5.34 & 8.71 \\
\hline $1.2 \mathrm{~mm}$ & 349.26 & 464.20 & 247.57 & 70.74 & 9.63 & 5.00 & 8.52 \\
\hline
\end{tabular}

\section{BP Neural Network Model Optimized by GA}

The BP neural network is a multi-layer feedforward network composed of input layer, hidden layer, and output layer $[37,38]$. The initial weights/thresholds are randomly selected by system that are different between different each training. Therefore, the final weights/thresholds and models of the neural network obtained after training are different, especially when the training data are small. It is possible that the two neural network 
models are completely different, so the generalization ability of neural network is poor. When the training data are sufficient and extensive, although the difference between the neural network models after training is small, the training convergence speed will be too low. Using the genetic algorithm to search for the best initial weight/threshold value in the entire range of weight/threshold value, the error of BP neural network after training under the best initial weight/threshold value can be minimized. In this way, the difference of the BP neural network after training due to different initial weights/thresholds can be avoided, and the problem of network oscillation and non-convergence caused by improper initial weights/threshold values can also be prevented [39,40]. The process of optimizing the initial weight/threshold of the BP neural network by GA is shown in Figure 6.

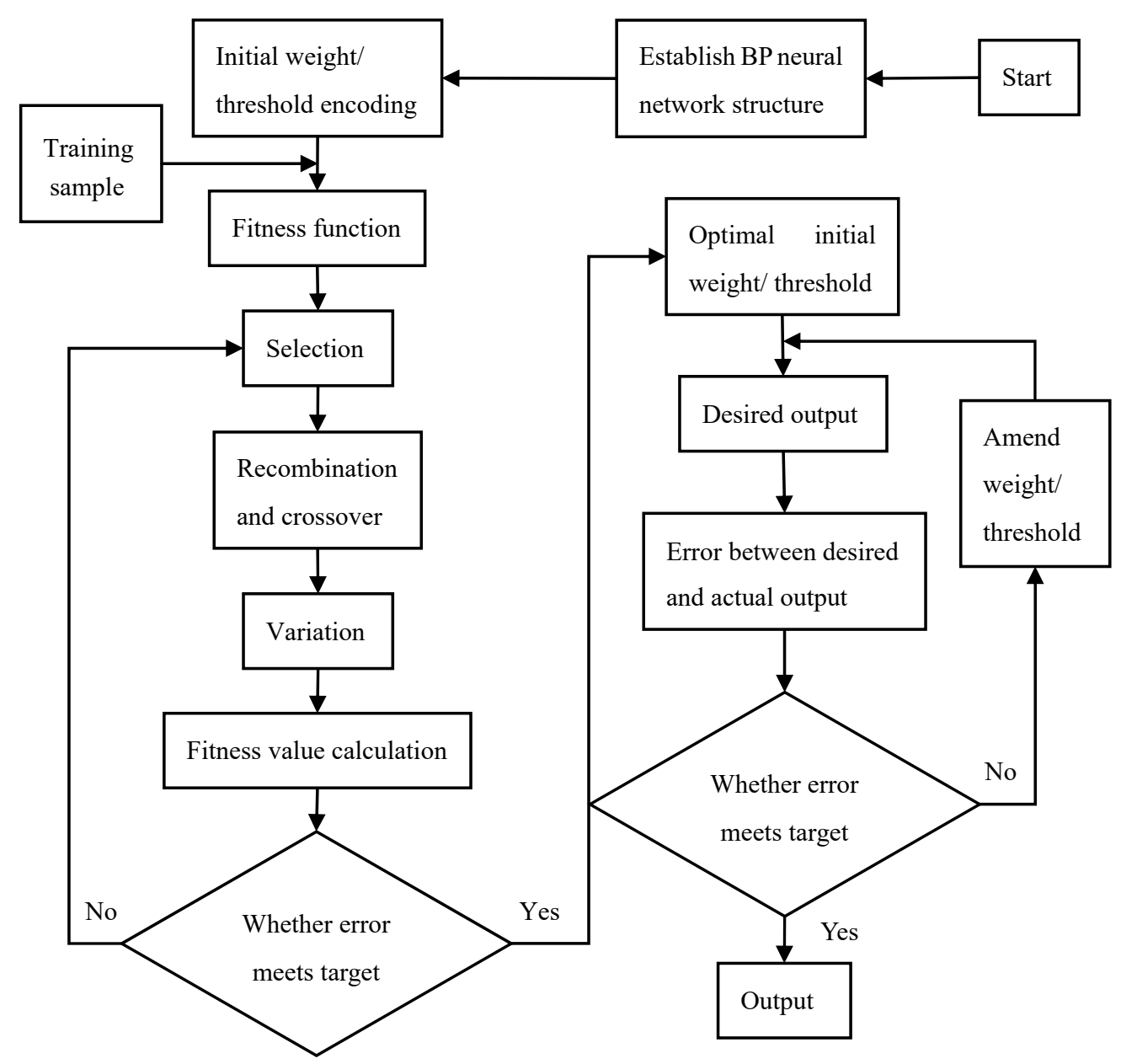

Figure 6. Flow chart of BP network optimized by genetic algorithm.

\subsection{Structure of BP Neural Network}

(1) Number of neurons in the input layer: When the diameter of the SMA wire is constant, the SMA constitutive relationship after stable performance is mainly affected by the loading rate and loading history. Therefore, the following variables can be determined as the input neurons of the BP neural network:

$$
x_{1}=v, x_{2}=\sigma_{t-2}, x_{3}=\varepsilon_{t-2}, x_{4}=\sigma_{t-1}, x_{5}=\varepsilon_{t-1}, x_{6}=\varepsilon_{t}
$$

where $v$ is the loading rate of the SMA wire, $\sigma_{i}$ and $\varepsilon_{i}$ represent the stress and strain at time $I$, respectively.

(2) Number of neurons in the output layer: The variable required by the SMA constitutive model is the stress $\sigma_{t}$ at time $\mathrm{t}$, so $y=\sigma_{t}$ is determined as the output neuron of the BP neural network. 
(3) Number of neurons in the hidden layer: The number of neurons in the hidden layer is a complex problem to be solved in the BP neural network. Currently, estimation methods [12] are usually used to determine the number of neurons in the hidden layer, and that is taken as 20.

(4) Neuron activation function: The activation function of the hidden layer neuron of the BP neural network is selected as logsig, and the activation function of the output layer neuron is selected as purelin.

\subsection{Training Sample Collection and Processing}

First, the training data is collected based on the test data of SMA wires. Since the SMA wire with a diameter of $1.0 \mathrm{~mm}$ is selected for structural vibration control, the neural network constitutive model for SMA with a diameter of $1.0 \mathrm{~mm}$ should be established. There are 48 working conditions in the SMA material property test, among which there are 12 working conditions with a diameter of $1.0 \mathrm{~mm}$, and 4 of them are selected as the inspection data, respectively: (1) The diameter is $1.0 \mathrm{~mm}$, the loading rate is $10 \mathrm{~mm} / \mathrm{min}$, and the strain amplitude is $6 \%$; (2) The diameter is $1.0 \mathrm{~mm}$, the loading rate is $30 \mathrm{~mm} / \mathrm{min}$, and the strain amplitude is $6 \%$; (3) The diameter is $1.0 \mathrm{~mm}$, the loading rate is $60 \mathrm{~mm} / \mathrm{min}$, and the strain amplitude is $6 \%$; (4) The diameter is $1.0 \mathrm{~mm}$, the loading rate is $90 \mathrm{~mm} / \mathrm{min}$, and the strain amplitude is $6 \%$. The remaining 8 working conditions are for training data.

Then, the training data is normalized to obtain the samples required for training the $\mathrm{BP}$ neural network. Since the hidden layer neurons use the sigmoid activation function that is a saturation zone near the function value 0 and 1 , and the function value changes very slowly, the normalization process can prevent the input data from entering the saturated region due to excessive absolute value.

\subsection{Optimization Parameters of GA}

The initial weight/threshold value of the unoptimized BP neural network is randomly assigned by the system, and that of the optimized BP neural network is determined by GA. According to the $\mathrm{BP}$ neural network structure, the weights to be determined in the BP neural network are $6 \times 20+20 \times 1=140$, and there are $20+1=21$ thresholds to be determined. The variables of GA are weights and thresholds, so the total number of variables is 161 . Since the weight/threshold value can be any real number, in order to improve the accuracy and efficiency of the genetic algorithm, real-valued coding is used, and the chromosome length of the genetic algorithm is $140+21=161$. The objective function is the sum of squared errors between the expected output and the actual output obtained from the input of the training sample. Other parameters of GA: the initial population number is 40 ; the random traversal sampling selection function is used, and the generation gap is 0.9 ; the intermediate recombination crossover operator is selected; the real-valued mutation operator is used, and the mutation probability is 0.01 ; the maximum genetic algebra is 50 .

\subsection{Simulation Results and Analysis}

The first step is to create a BP neural network model of austenite SMA, and a BP neural network model optimized by GA. MATLAB2013b neural network toolbox and gatbx toolbox are used to write simulation program code. The data of the last cycle of the test condition are used as the training sample of BP neural network. The training function is selected as trainlm, the maximum number of training times is 1000 , the target error is $10^{-5}$, and the learning rate is 0.1 . The topological structure of BP neural network can be obtained by running the program as shown in Figure 7, and the validation performance chart is shown in Figure 8. 


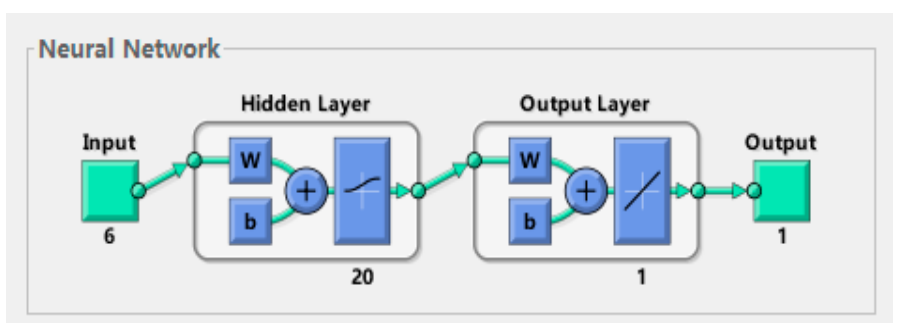

Figure 7. BP neural network topology.

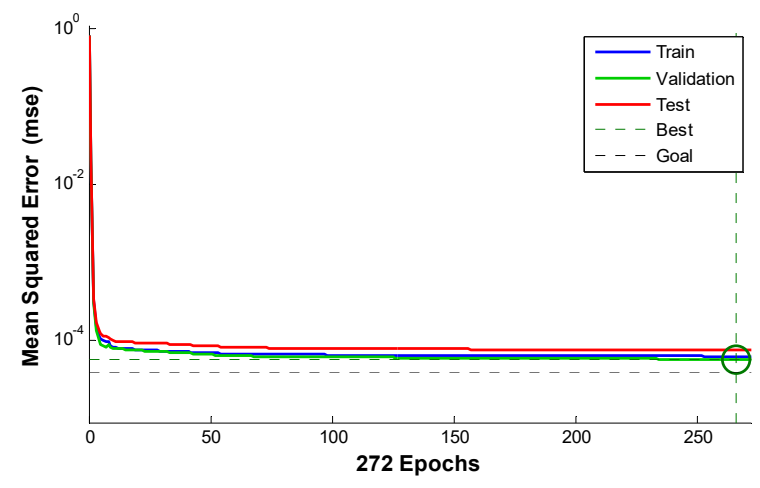

Figure 8. Validation Performance Chart.

The second step is to compare the accuracy of unoptimized and optimized BP neural network models. Four groups of normalized inspection data are input into the unoptimized $\mathrm{BP}$ neural network and the optimized BP neural network in sequence, and the expected output is obtained respectively. The accuracy of the two constitutive models is obtained by comparing expected output with the actual output and error analysis.

Figure 9 is a comparison diagram of the BP neural network prediction curve and the experimental curve at the diameter of $1.0 \mathrm{~mm}$, loading rate of $90 \mathrm{~mm} / \mathrm{min}$, and strain amplitude of $6 \%$. It can be seen that, after each training, the BP neural network prediction curve without GA optimization has a large fluctuation range due to the randomness of the initial weight/threshold, but that optimized by GA is in good agreement with the test curve, avoiding the difference of the model obtained from each run of the BP neural network, and it is a constitutive model of SMA with good stability and high accuracy.

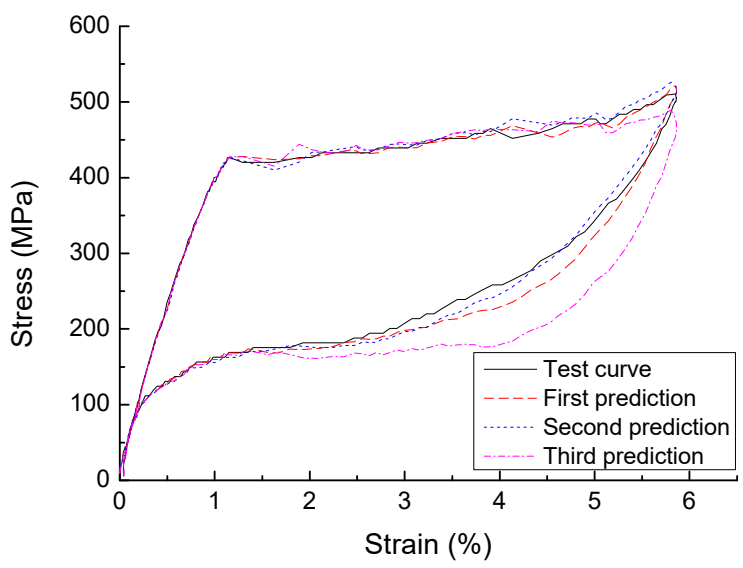

(a)

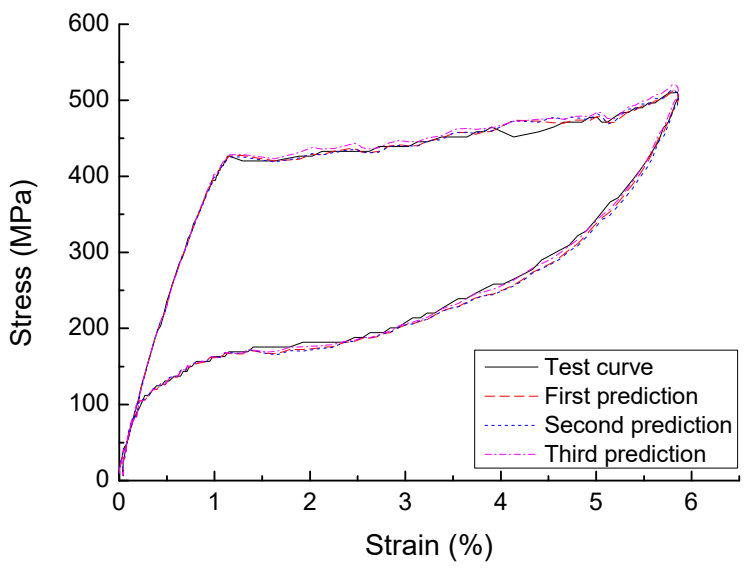

(b)

Figure 9. Comparison of BP network prediction curve and test curve (a) unoptimized BP network and (b) optimized BP network. 
Since the network structure of the unoptimized BP neural network is different each time, the unoptimized BP neural network with better prediction results is selected for comparison with the optimized BP neural network. Figure 10 shows the comparison and error of the test curve with the unoptimized and optimized neural network prediction curve under different loading rates when the diameter is $1.0 \mathrm{~mm}$ and the loading amplitude is $6 \%$. The average absolute percentage error $E_{\mathrm{P}}$ and $E_{\mathrm{GP}}$ of the prediction results of the two BP neural network models at the loading rate of $90 \mathrm{~mm} / \mathrm{min}$ are:

$$
\begin{gathered}
E_{\mathrm{P}}=\frac{1}{n} \sum_{i=1}^{n} \frac{\left|Y_{i}-Y_{\mathrm{P} i}\right|}{Y_{i}}=2.72 \% \\
E_{\mathrm{GP}}=\frac{1}{n} \sum_{i=1}^{n} \frac{\left|Y_{i}-Y_{\mathrm{GP} i}\right|}{Y_{i}}=2.13 \%
\end{gathered}
$$

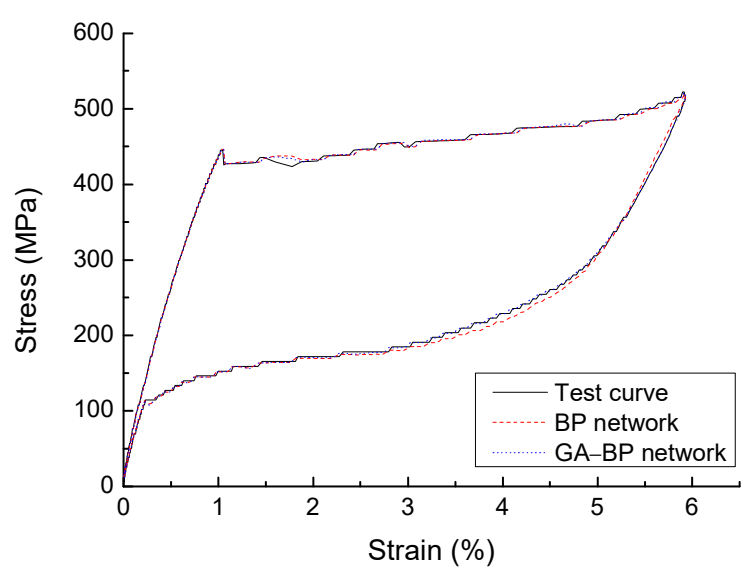

(a)

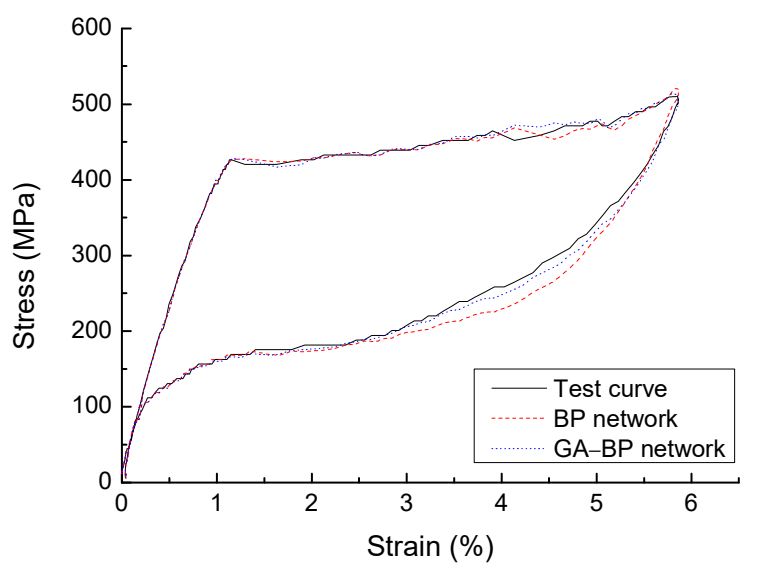

(c)

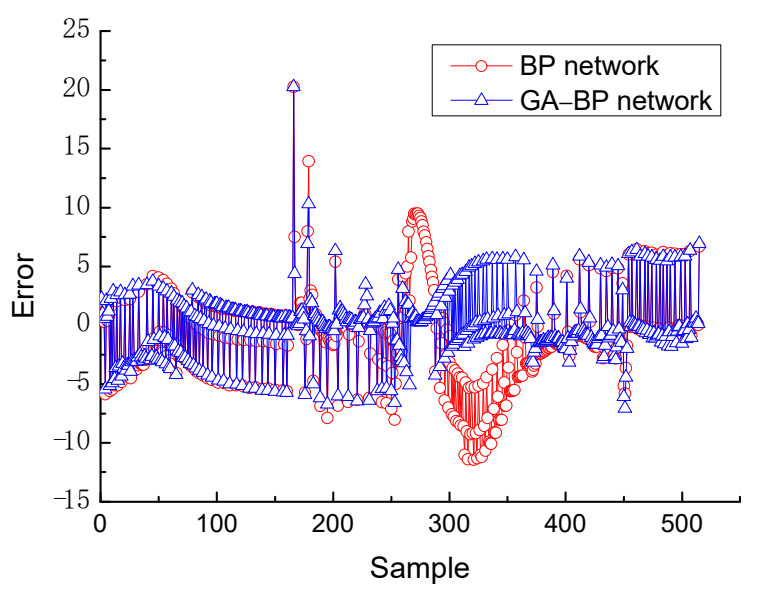

(b)

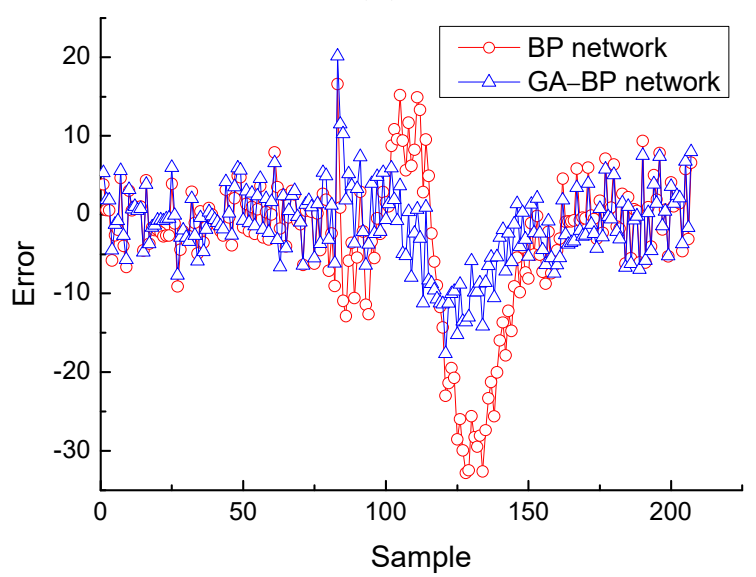

(d)

Figure 10. Comparison and corresponding error between test curve and prediction curves of un-optimized and optimized BP network by GA, (a) constitutive curves at $30 \mathrm{~mm} / \mathrm{min}$, (b) error at $30 \mathrm{~mm} / \mathrm{min}$, (c) constitutive curves at $90 \mathrm{~mm} / \mathrm{min}$, (d) error at $90 \mathrm{~mm} / \mathrm{min}$.

The linear coefficient of correlation $\gamma \mathrm{P}$ and $\gamma \mathrm{GP}$ of two prediction results are:

$$
\gamma_{\mathrm{P}}=\frac{\sum_{i=1}^{n}\left(Y_{i}-\bar{Y}\right)\left(Y_{\mathrm{P} i}-\bar{Y}_{\mathrm{P}}\right)}{\sqrt{\sum_{i=1}^{n}\left(Y_{i}-\bar{Y}\right)^{2} \cdot \sum_{i=1}^{n}\left(Y_{\mathrm{P} i}-\bar{Y}_{\mathrm{P}}\right)^{2}}}=0.9983
$$




$$
\gamma_{\mathrm{GP}}=\frac{\sum_{i=1}^{n}\left(Y_{i}-\bar{Y}\right)\left(Y_{\mathrm{GP} i}-\bar{Y}_{\mathrm{GP}}\right)}{\sqrt{\sum_{i=1}^{n}\left(Y_{i}-\bar{Y}\right)^{2} \cdot \sum_{i=1}^{n}\left(Y_{\mathrm{GP} i}-\bar{Y}_{\mathrm{GP}}\right)^{2}}}=0.9995
$$

The root mean square error $\sigma_{\mathrm{P}}$ and $\sigma_{\mathrm{GP}}$ of two prediction results are:

$$
\begin{gathered}
\sigma_{\mathrm{P}}=\sqrt{\frac{\sum_{i=1}^{n}\left(Y_{i}-Y_{\mathrm{P} i}\right)^{2}}{n}}=9.76 \\
\sigma_{\mathrm{GP}}=\sqrt{\frac{\sum_{i=1}^{n}\left(Y_{i}-Y_{\mathrm{GP} i}\right)^{2}}{n}}=5.43
\end{gathered}
$$

where $Y_{i}$ and $\bar{Y}$ are the sample and mean stress measured in the experiment, $Y_{\mathrm{P} i}$ and $\bar{Y}_{\mathrm{P}}$ are the sample and mean stress predicted by the BP neural network model, and $Y_{\mathrm{GP} i}$ and $\bar{Y}_{\mathrm{GP}}$ are the sample and mean stress predicted by the BP neural network model optimized by GA.

The analysis shows that: (a) With the change of SMA wire loading rate, the optimized BP neural network model can track the force behavior of SMA well, and the average absolute percentage error is $2.13 \%$, the linear coefficient of correlation is 0.9995 and the root mean square error is 5.43 . This shows that the neural network constitutive model based on GA optimization can well describe the change of SMA superelastic performance with loading rate, better predict the superelastic restoring force of SMA under repeated loading, and is a good rate-dependent dynamic constitutive model. (b) Although the unoptimized BP constitutive curve with better prediction effect is compared with the BP constitutive curve optimized by GA, the accuracy of the optimized model is still higher than that of the unoptimized model. The error distribution of BP constitutive curve optimized by GA and the experimental constitutive curve is relatively concentrated. Only the error of individual sample points is far from 0 , and the absolute maximum error is smaller than that of the unoptimized BP network. The error distribution between the unoptimized neural network curve and the experimental curve is relatively scattered. More importantly, the optimal initial weight/threshold value obtained by optimization replaces the random value assigned by the system, so that the BP neural network has a fixed optimal initial weight/threshold value, avoiding the difference of the BP neural network after each training.

\section{Optimization Control of Spatial Structure with SMA Wires}

\subsection{Dynamic Equation of SMA Passive Control System}

According to the basic theory of structural dynamics [41,42], the motion equation of a structure equipped with an austenitic SMA passive control system under seismic excitation can be expressed as:

$$
M \ddot{x}+C \dot{x}+K x=-M I \ddot{x}_{\mathrm{g}}+u
$$

where $\ddot{x}_{\mathrm{g}}$ is the acceleration of ground motion under seismic excitation; $M, K$, and $C$ are the mass matrix, stiffness matrix and damping matrix of the structure, respectively; $\ddot{x}, \dot{x}$, and $x$ are the acceleration, velocity and displacement column vector of the structure relative to the ground; $I$ is the unit column vector; $u$ is the passive control force column vector of the SMA wires acting on the structural nodes.

$$
\begin{gathered}
u=\left\{u_{1}{ }^{T}, u_{2}{ }^{T} \cdots u_{n}{ }^{T}\right\}^{T} \\
\left\{\begin{array}{c}
u_{i}=\sum_{j}\left\{F_{i j} \cdot \cos \theta_{i j}\right\} \quad \varepsilon_{i j}>0 \\
u_{i}=0 \quad \varepsilon_{i j} \leq 0
\end{array}\right. \\
F_{i j}=\sigma_{i j} \cdot A_{i j}
\end{gathered}
$$


where $u_{i}$ is the control force column vector of SMA wire acting on the structure node $i$; $\theta_{i j}$ represents the direction cosine column vector of the $j$-th SMA wire connected to the structural node $i$ and the coordinate axes $\mathrm{X}, \mathrm{Y}$, and $\mathrm{Z} ; F_{i j}$ represents the tension of the $j$-th SMA wire connected to the structural node $i ; \sigma_{i j}, \varepsilon_{i j}$, and $A_{i j}$ refer to the tensile stress, tensile strain and cross-sectional area of the $j$-th SMA wire connected to the structural node $i$.

MATLAB is used to compile the Newmark- $\beta$ method calculation program to analyze the dynamic time history of the space model structure with the SMA passive control system. The simulation time step interval is very small, and the earthquake action is also very small in the first two-time steps, that is, the force of the SMA wire is very small in the initial stage. Therefore, it is approximately considered that in the first two-time steps of the earthquake, the $\sigma_{i j}$ and $\varepsilon_{i j}$ of all SMA wires are 0 , and the structure is in an uncontrolled state. Stress $\sigma_{i j}$ at any time later can be obtained via SMA BP network constitutive model optimized by GA. The vibration velocity at time $t$, the stress and strain at time $t-1$ and $t-2$, and the strain at time $t$ are input into the optimized BP network constitutive model. Then, the stress of the SMA wire at time $t$ can be obtained. Among them, the strain $\varepsilon_{i j}(\mathrm{t})$ of SMA wire at any time can be obtained from the lateral displacement difference of the nodes at both ends of the SMA wire, and the strain of the oblique SMA wire arranged in the XY plane of the structure can be obtained by the following formula:

$$
\begin{cases}\varepsilon_{i j}(t)=\varepsilon_{k j}(t)=\frac{\sqrt{h^{2}+\left(w+s_{k}(t)-s_{i}(t)\right)^{2}}-\sqrt{h^{2}+w^{2}}}{\sqrt{h^{2}+w^{2}}} & s_{k}(t)-s_{i}(t)>0 \\ \varepsilon_{i j}(t)=\varepsilon_{k j}(t)=\frac{\sqrt{h^{2}+w^{2}}-\sqrt{h^{2}+\left(w+s_{k}(t)-s_{i}(t)\right)^{2}}}{\sqrt{h^{2}+w^{2}}} & s_{k}(t)-s_{i}(t) \leq 0\end{cases}
$$

where $h$ and $w$ are the layer height and single-span span of the structure respectively; when the angle between the $j$-th SMA wire and the positive $X$ direction is less than $90^{\circ}$, $S_{k}(\mathrm{t})$ refers to the lateral horizontal displacement of the $k$-th structural node connected to the upper end of the SMA wire, $S_{i}(\mathrm{t})$ refers to the lateral horizontal displacement of the $i$-th structural node connected to the lower end of the SMA wire. When the angle between the $j$-th SMA wire and the positive $\mathrm{X}$ direction is greater than $90^{\circ}, S_{k}(\mathrm{t})$ refers to the lateral horizontal displacement of the $k$-th structural node connected to the lower end of the SMA wire, and $S_{i}(\mathrm{t})$ refers to the lateral horizontal displacement of the $i$-th structural node connected to the upper end of the SMA wire.

The structural dynamic time history analysis program is compiled to solve the seismic response of the structure. First, the genetic algorithm is employed to optimize the BP neural network constitutive model of SMA wire and the "save" command is used to save the optimized BP neural network model in the form of data structure. Then, the Newmark- $\beta$ algorithm program is written to solve the dynamic Equation (10), in which the control force $u$ can be obtained by calling the BP neural network model optimized by GA.

\subsection{Optimization Criteria}

The sum of the lateral displacements of the structure is taken as the optimized objective function, that is, the optimization criterion is

$$
\begin{gathered}
J=\sum_{i}\left|\Delta_{i}\right|=\sum_{i}\left|S_{i}-S_{i-1}\right| \\
S_{i}=\frac{\sum_{j} S_{i j}}{\sum_{j} j}
\end{gathered}
$$

where $J$ is the objective function value; $\left|\Delta_{i}\right|$ represents the absolute lateral displacement of the $i$-th layer; $S_{i}$ represents the storey drift of the $i$-th layer, and it is the average of the lateral displacement of all nodes of the $i$-th layer; $S_{i j}$ denotes the absolute lateral displacement of the node $j$ of the $i$-th layer. The smaller the objective function value $J$, the smaller the 
dynamic response of the structure, and the better the control effect of the corresponding SMA wire arrangement on the structure. Based on the basic principles of GA, the following fitness function can be designed:

$$
\text { Fit }=\frac{1}{J}=\frac{1}{\sum_{i}\left|S_{i}-S_{i-1}\right|}
$$

this fitness function meets the design requirements of single value, continuous, nonnegative, and maximization. The larger the fitness value corresponding to GA individual, the smaller the objective function value, and the better the corresponding SMA configuration scheme.

\subsection{Optimization Control and Analysis of Spatial Structure}

The spatial model structure is 2 spans along the $X$ direction with each span of $500 \mathrm{~mm}$ in length, and along the $Z$ direction is 1 span, the length is $600 \mathrm{~mm}$, the height is 3 layers, and the height of each layer is $500 \mathrm{~mm}$. In order to facilitate the installation and connection of the SMA wire, each layer of 6 nodes has an additional weight of $1 \mathrm{~kg}$, and there are spiral holes for fixing the SMA wire. All rods are Q235 round steel pipes with an outer diameter of $10 \mathrm{~mm}$ and a wall thickness of $1 \mathrm{~mm}$. The elastic modulus is $206 \mathrm{GPa}$, the Poisson's ratio is 0.3 , and the density is $7.85 \times 10^{3} \mathrm{~kg} / \mathrm{m}^{3}$. The following assumptions are made in the analysis of structural seismic response: (a) All masses are concentrated at the nodes of each floor; (b) The initial working temperature of SMA wire is constant in its cross section and length direction.

As the vertical and horizontal SMA wires in the $X Y$ plane and the SMA wires in the $Y Z$ plane have little shock absorption effect on the structure under the action of the horizontal earthquake in the $X$ direction. The SMA wires at these positions are not considered here. Only the diagonal SMA wires in the XY plane are considered, so the node numbers of the spatial model structure and the possible positions of the SMA wires are shown in Figure 11. The positions of the red lines in the figure represent all the possible positions of the SMA wires with a total number of 24 .

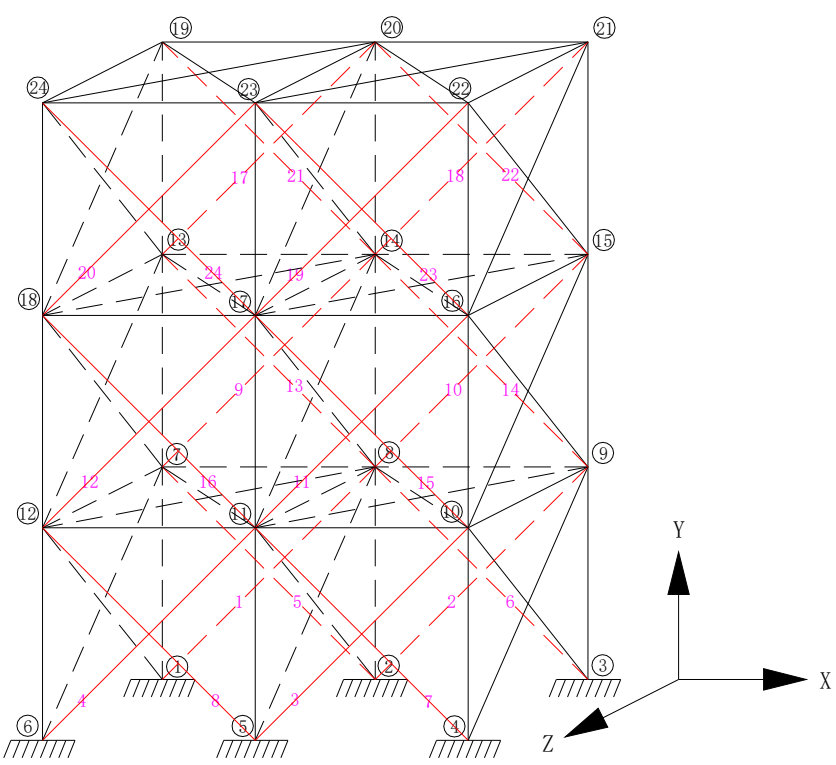

Figure 11. Possible locations of austenitic SMA wires and structural node numbers.

The operating parameters of GA are set as follows: real-valued coding is used, the initial population size is 40 , the maximum number of generations is 50 , and the crossover probability is 0.8 . When the generation required to maintain the optimal individual unchanged does not exceeds 5 , the mutation probability $\mathrm{P}_{\mathrm{m}}$ is 0.05 . When the generation required to maintain the optimal individual unchanged exceeds 20 , the mutation probabil- 
ity $\mathrm{GP}_{\mathrm{m}}$ is 0.2 . When the optimal individual does not change and the required generation is between 5 and 20, the mutation probability is taken by linear interpolation between $P_{m}$ and $\mathrm{GP}_{\mathrm{m}}$.

The El Centro wave with the duration of $20 \mathrm{~s}$, the interval of $0.02 \mathrm{~s}$, and the peak acceleration amplitude of $200 \mathrm{gal}$ is selected as the seismic excitation of the spatial structure along the $X$ direction. In the structure, 2, 4, 6, 8, 12, 16, 20, and 24 SMA wires are arranged for optimizing the position. The change of the objective function value with the evolutionary generation is shown in Figure 12. Table 5 presents the optimal positions of different numbers of SMA wires in the spatial structure, the value of the objective function, and the corresponding shock absorption effects.

Table 5. Optimal results of austenite SMA wires with different amounts.

\begin{tabular}{cccc}
\hline Number of SMA Wires & Position Optimization Result & Objective Function Value (mm) & Suppression Ratio (\%) \\
\hline 0 (non-control) & $/$ & 48.3 & $/$ \\
2 & 4,15 & 33.7 & 30.23 \\
4 & $4,6,12,14$ & 26.8 & 44.51 \\
6 & $2,6,7,13,14,20$ & 23.5 & 51.35 \\
8 & $4,7,8,13,14,15,21,24$ & 21.6 & 55.28 \\
12 & $2,8,9,10,11,13$ & 21.2 & 56.11 \\
& $14,15,19,20,22,23$ & & 52.80 \\
& $2,3,4,5,9,10,11,12,13$ & & \\
20 & $14,15,16,17,19,21,24$ & 22.8 & 45.55 \\
24 & $1,3,4,5,6,9,10,11,12,13,14$ & & 43.89 \\
\hline
\end{tabular}

It can be seen from the optimization results that with the increase of genetic evolution generations, the optimal value of the objective function gradually decreases, and the average value of the objective function basically shows a gradually decreasing trend, which indicates that the optimal value and the average value are in a gradual convergence. During the process, the value of the objective function changes less and less. The optimized arrangement of the SMA wire has a better suppression effect on the seismic response of the space structure, but it is not that the more the number of SMA wires installed, the better the shock absorption effect. When the number of the SMA wire exceeds a certain number, the shock absorption effect decreases. When 4 austenitic SMA wires are arranged, the SMA wire layout optimized by GA can reduce the storey drift of the structure by $44.51 \%$. Therefore, for the consideration of damping efficiency and economy, 4 SMA wires are selected to passively control the structure. The optimized layout is shown in Figure 13a, and the shaking table test model is shown in Figure 13b.

Using node 24 , node 18 , and node 12 to analyze the acceleration response and displacement response of the structure with and without control, the peak response is shown in Tables 6 and 7, and the time history curve of storey drift response and interlayer acceleration response is shown in Figure 14. It can be seen that the simulation results are in good agreement with the test results, which supports the rationality and feasibility of MATLAB simulation model for the seismic response analysis of space structure with SMA wires based on BP neural network. Meanwhile, the suppression effect of displacement response is more obvious than that of the acceleration response, the bottom layer has the best damping effect, the storey drift reduction rate is $52.98 \%$, and the interlayer acceleration reduction rate is $25.89 \%$. 


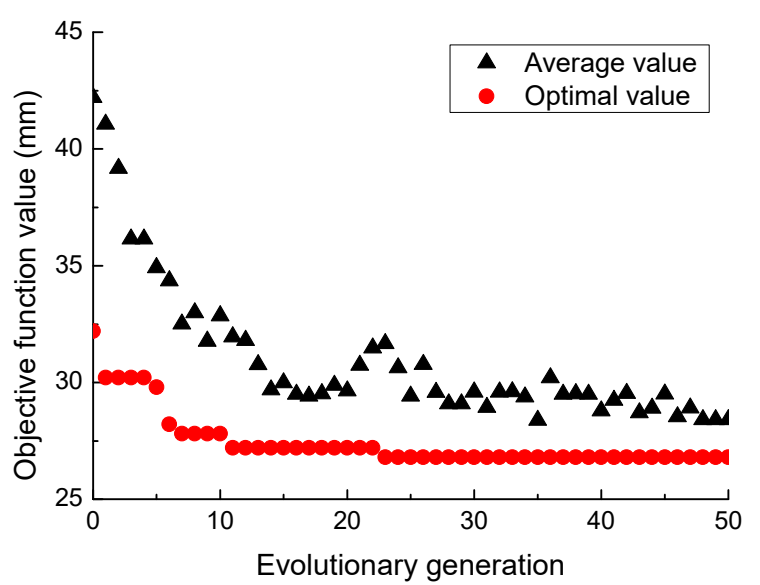

(a)

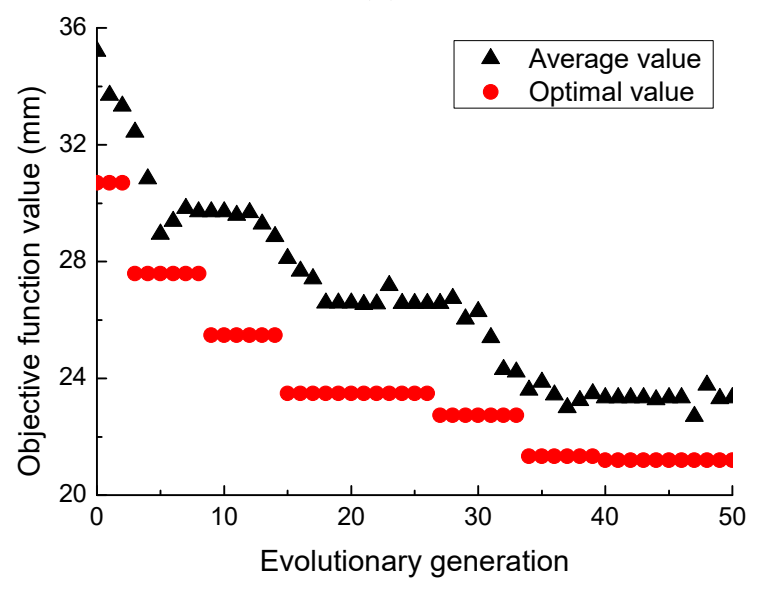

(c)

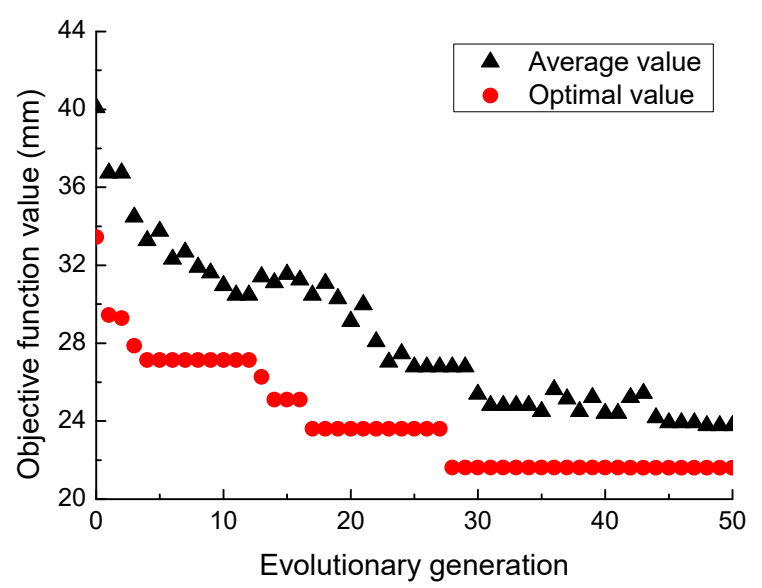

(b)

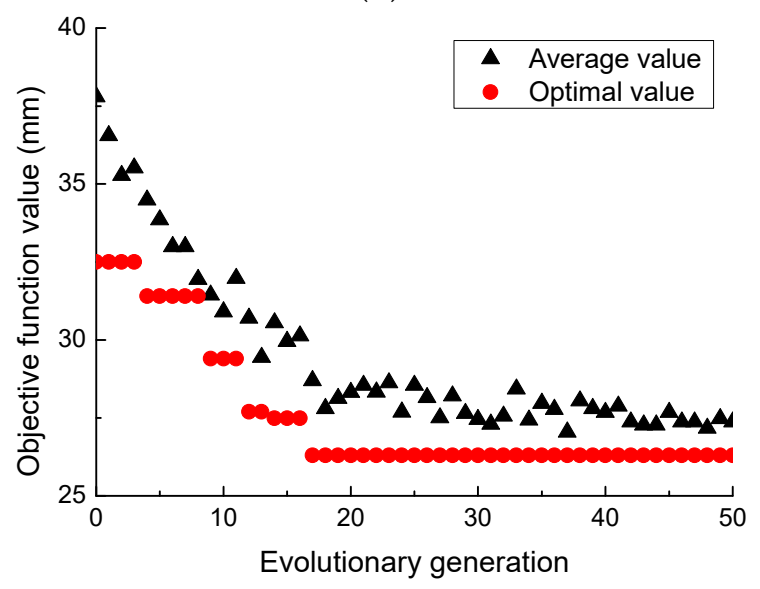

(d)

Figure 12. Objective function values with the change of evolutionary generations under different amounts of SMA wire, (a) 4 SMA wires, (b) 8 SMA wires, (c) 12 SMA wires, (d) 20 SMA wires.

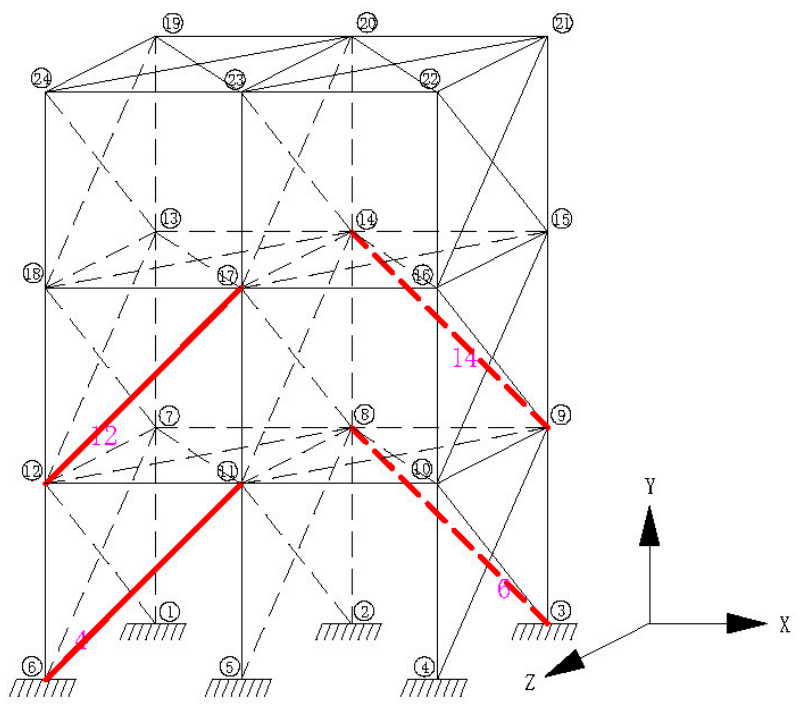

(a)

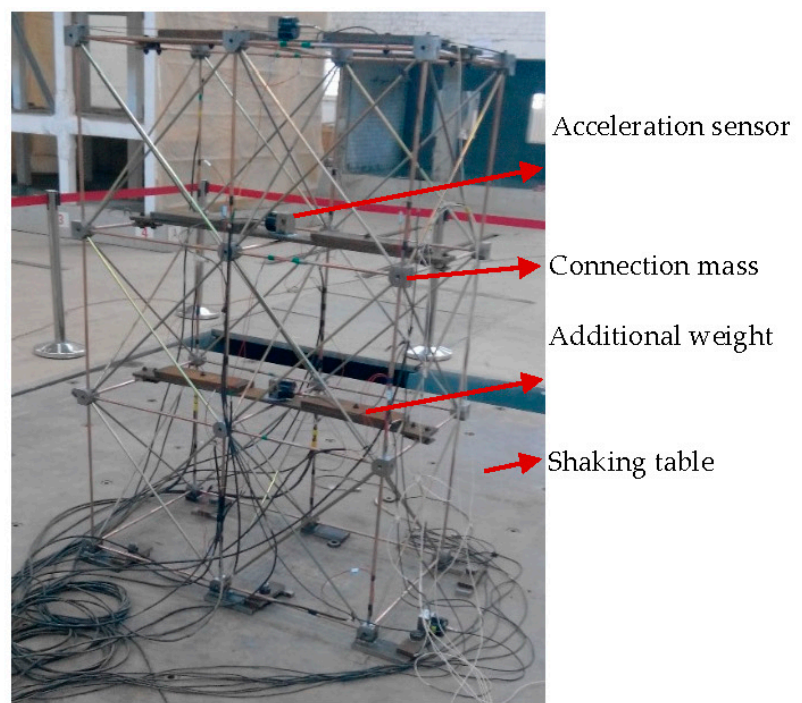

(b)

Figure 13. Spatial structure model with 4 austenite SMA wires (a) optimal position and (b) shaking table test. 
Table 6. Peak storey drift and corresponding suppression rates under optimal and uncontrolled conditions.

\begin{tabular}{cccccc}
\hline \multirow{2}{*}{ Floor } & \multicolumn{2}{c}{ Non-Control (mm) } & \multicolumn{2}{c}{ Optimal Placement } & \multicolumn{2}{c}{$\begin{array}{c}\text { Suppression Rate for } \\
\text { Simulation Result (\%) }\end{array}$} \\
\cline { 2 - 5 } & Simulation Result & Test Result & Simulation Result & Test Result & 52.98 \\
1 & 23.052 & 25.182 & 10.838 & 13.431 & 46.78 \\
2 & 16.352 & 15.258 & 8.702 & 9.287 & 6.484 \\
3 & 8.910 & 7.641 & 7.236 & 6.49 & 18.79 \\
\hline
\end{tabular}

Table 7. Peak interlayer acceleration and corresponding suppression rates under optimal and uncontrolled conditions.

\begin{tabular}{|c|c|c|c|c|c|}
\hline \multirow{2}{*}{ Floor } & \multicolumn{2}{|c|}{ Non-Control (m/s²) } & \multicolumn{2}{|c|}{ Optimal Placement $\left(\mathrm{m} / \mathrm{s}^{2}\right)$} & \multirow{2}{*}{$\begin{array}{l}\text { Suppression Rate for } \\
\text { Simulation Result (\%) }\end{array}$} \\
\hline & Simulation Result & Test Result & Simulation Result & Test Result & \\
\hline 1 & 4.734 & 4.407 & 3.508 & 3.116 & 25.89 \\
\hline 2 & 4.028 & 3.696 & 3.153 & 2.519 & 21.73 \\
\hline 3 & 2.517 & 1.719 & 2.068 & 1.423 & 17.83 \\
\hline
\end{tabular}

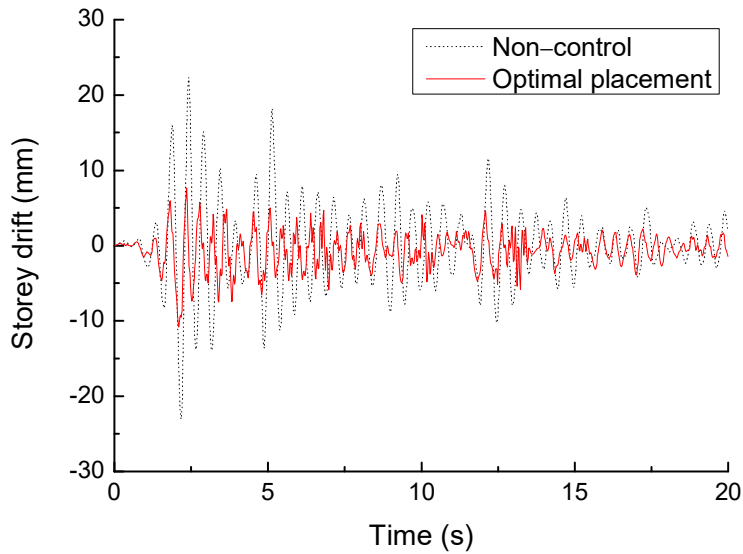

(a)

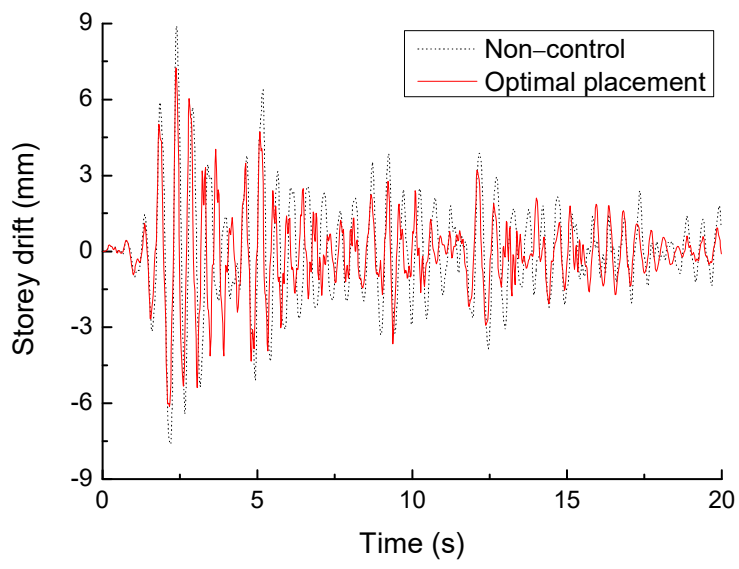

(c)

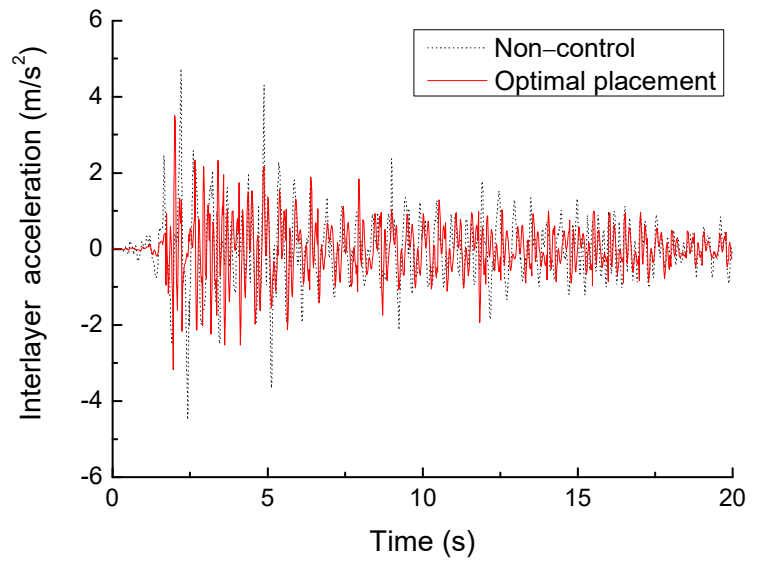

(b)

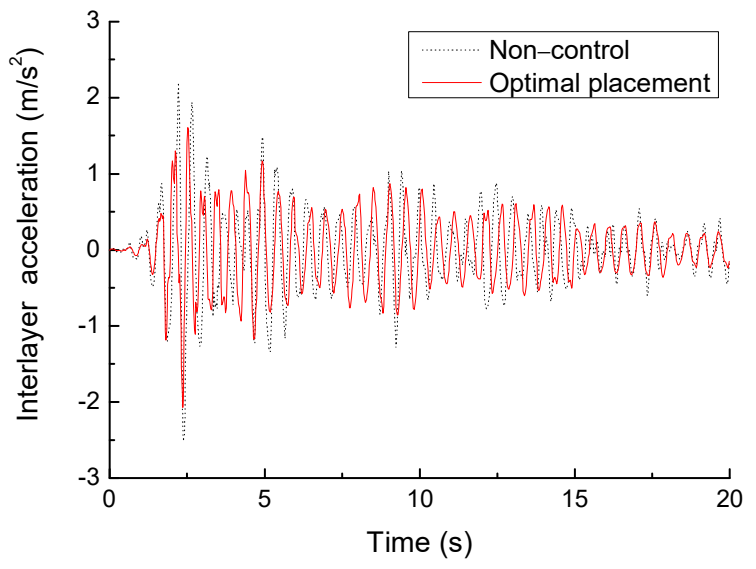

(d)

Figure 14. Time history curves of seismic response of spatial model structure with and without control, (a) storey drift of first floor, (b) interlayer acceleration of first floor, (c) storey drift of third floor, (d) interlayer acceleration of third floor.

\section{Conclusions}

(1) The mechanical tests of SMA wires show that with the increase of the number of cycles, the performance of SMA wires gradually stabilized, the stress-strain curve gradually becomes smooth, the accumulated residual deformation increases gradually, but the residual deformation of single cycle gradually decreases. After 15 cycles, the stressstrain curve tends to be stable, and the residual strain of single cycle is basically 0 . 
With the increase of strain amplitude, the energy dissipation capacity of SMA wires increases obviously. With the increase of loading rate and diameter, the energy dissipation capacity of SMA wires decreases, but not obviously. The strain amplitude is the most prominent factor affecting the energy dissipation capacity of SMA wires.

(2) Taking the material test data of SMA wires as the training sample and test sample of the BP neural network, the BP neural network prediction model optimized by genetic algorithm is established. The simulation results show that the prediction curve of optimized BP neural network is in good agreement with the test curve, and the average absolute percentage error is only $2.13 \%$, the linear coefficient of correlation is 0.9995 , and the root mean square error is 5.43 . Thus, the model can well reflect the effect of loading velocity on the superelastic properties of SMA wires and is a velocity-dependent dynamic constitutive model with high precision for SMA.

(3) Since the initial weight/threshold is determined by the genetic algorithm, the optimized BP neural network avoids the difference of the prediction model in each run and reduces the phenomenon of network oscillation and non-convergence caused by the improper value of weight/threshold. Compared with the unoptimized BP neural network, it can predict the hysteretic behavior of SMA with better stability and higher accuracy.

(4) The BP neural network optimized by GA was employed to trace the stress-strain curve, and the optimization analysis of the SMA wires in a spatial structure model was carried out under the different seismic excitation. The simulation results are in good agreement with the test results, which supports the rationality and feasibility of MATLAB simulation model for the seismic response analysis of space structure with SMA wires based on BP neural network. Moreover, the results also show that the SMA wires after optimization can effectively reduce the seismic response of the structure, but it is not the case that the more SMA wires, the better the shock absorption effect. When the number of SMA wires exceeds a certain number, the vibration reduction effect gradually decreases. Therefore, the damping effect can be obtained economically and effectively only when the number and location of SMA wires are properly configured. When four SMA wires are arranged, a satisfactory control effect can be gained, the reduction rate of the sum of storey drift can reach $44.51 \%$, and the reduction rate of storey drift and acceleration response at first storey are $52.98 \%$ and $25.89 \%$ respectively.

Author Contributions: The research was conceptualized by M.Z. and S.W., M.Z., D.W. and L.Z. carried out the mechanical property test of SMA. D.W. developed the preliminary numerical models. The numerical models were verified by J.L., D.W. and X.C. The draft manuscript was completed with the contribution of M.Z., X.C. and L.Z. The manuscript was revised and reviewed by all authors. All authors have read and agreed to the published version of the manuscript.

Funding: The research described in this paper was financially supported by National Natural Science Foundation of China (51678480), Science and Technology Project of ministry of Housing and Urban-rural Development (2020-K-127), Henan province key projects of science and technology (212102310976, 202102310248), Ningxia natural science foundation(2021AAC03189), Zhumadian major projects of science and technology (19005), Cultivating Project of National Natural Science Fund (XKPY-202009), Training program for young backbone teachers in Colleges and universities of Henan Province.

Institutional Review Board Statement: Not applicable.

Informed Consent Statement: Not applicable.

Data Availability Statement: Not applicable.

Conflicts of Interest: The authors declare no conflict of interest. 


\section{References}

1. Wang, S.L. Application of Shape Memory Alloy in the Structure Control; Shaanxi Science \& Technology Press: Xi'an, China, 2000. (In Chinese)

2. Zhou, B.; Yoon, S.H.; Leng, J.S. A three-dimensional constitutive model for shape memory alloy. Smart Mater. Struct. 2009, 18, 095016. [CrossRef]

3. Kosel, F.; Videnic, T. Generalized Plasticity and Uniaxial Constrained Recovery in Shape Memory Alloys. Mech. Adv. Mater. Struct. 2007, 14, 3-12. [CrossRef]

4. Ding, Y.L.; Chen, X.; Li, A.Q.; Zuo, X.B. A new isolation device using shape memory alloy and its application for long-span structures. Earthq. Eng. Eng. Vib. 2011, 10, 239-252. [CrossRef]

5. Li, T.; Wang, S.L.; Yang, T. Experiment and Simulation Study on Vibration Control of an Ancient Pagoda with Damping Devices. Int. J. Struct. Stab. Dyn. 2018, 18, 1850120. [CrossRef]

6. Habieb, A.B.; Valente, M.; Milani, G. Hybrid seismic base isolation of a historical masonry church using unbonded fiber reinforced elastomeric isolators and shape memory alloy wires. Eng. Struct. 2019, 196, 109281. [CrossRef]

7. Dehghani, A.; Aslani, F. Crack recovery and re-centring performance of cementitious composites with pseudoelastic shape memory alloy fibres. Constr. Build. Mater. 2021, 298, 123888. [CrossRef]

8. Rezapour, M.; Ghassemieh, M.; Motavalli, M.; Shahverdi, M. Numerical Modeling of Unreinforced Masonry Walls Strengthened with Fe-Based Shape Memory Alloy Strips. Materials 2021, 14, 2961. [CrossRef]

9. Siddiquee, K.N.; Billah, A.M.; Issa, A. Seismic collapse safety and response modification factor of concrete frame buildings reinforced with superelastic shape memory alloy (SMA) rebar. J. Build. Eng. 2021, 42, 102468. [CrossRef]

10. Schranz, B.; Michels, J.; Czaderski, C.; Motavalli, M.; Vogel, T.; Shahverdi, M. Strengthening and prestressing of bridge decks with ribbed iron-based shape memory alloy bars. Eng. Struct. 2021, 241, 112467. [CrossRef]

11. Peng, Z.; Wei, W.; Yibo, L.; Miao, H. Cyclic behavior of an adaptive seismic isolation system combining a double friction pendulum bearing and shape memory alloy cables. Smart Mater. Struct. 2021, 30, 075003. [CrossRef]

12. Zhan, M.; Wang, S.L.; Zhang, L.Z.; Chen, Z.F. Experimental evaluation of smart composite device with shape memory alloy and piezoelectric materials for energy dissipation. J. Mater. Civ. Eng. ASCE 2020, 32, 04020079. [CrossRef]

13. Villoslada, A.; Escudero, N.; Martín, F.; Flores, A.; Rivera, C.; Collado, M.; Moreno, L. Position control of a shape memory alloy 565 actuator using a four-term bilinear PID controller. Sens. Actuators A Phys. 2015, 236, 257-272. [CrossRef]

14. Kha, N.B.; Ahn, K.K. Position Control of Shape Memory Alloy Actuators by Using Self Tuning Fuzzy PID Controller. In Proceedings of the 1st IEEE Conference on Industrial Electronics and Applications, Singapore, 24-26 May 2006; pp. 1-5.

15. Samadi, S.; Koma, A.Y.; Zakerzadeh, M.R.; Heravi, F.N. Control an SMA-actuated rotary actuator by fractional order PID 569 controller. In Proceedings of the 5th RSI International Conference on Robotics and Mechatronics (ICRoM), Tehran, Iran, 25-27 October 2017; p. 570.

16. Ma, N.; Song, G. Control of shape memory alloy actuator using pulse width modulation. Smart Mater. Struct. 2003, 12, 12712. [CrossRef]

17. Fan, Y.J.; Sun, K.Q.; Zhao, Y.J.; Yu, B.S. A simplified constitutive model of Ti-NiSMA with loading rate. J. Mater. Res. Technol. 2019, 8, 5374-5383. [CrossRef]

18. Videnic, T.; Brojan, M.; Kunavar, J.; Kosel, F. A Simple One-Dimensional Model of Constrained Recovery in Shape Memory Alloys. Mech. Adv. Mater. Struct. 2014, 21, 376-383. [CrossRef]

19. Falk, F. One-dimensional model of shape memory alloys. Arch Mech. 1983, 35, 63-84.

20. Abeyaratne, R.; Knowles, J.K. A continuum model of a thermoelastic solid capable of undergoing phase transitions. J. Mech. Phys. Solids 1993, 41, 541-571. [CrossRef]

21. Boyd, J.G.; Lagoudas, D.C. A thermodynamical constitutive model for shape memory materials, Part II The SMA composite material. Int. J. Plast. 1996, 12, 843-874. [CrossRef]

22. Brinson, L.C. One-Dimensional Constitutive Behavior of Shape Memory Alloys: Thermomechanical Derivation with NonConstant Material Functions and Redefined Martensite Internal Variable. J. Intell. Mater. Syst. Struct. 1993, 4, 229-242. [CrossRef]

23. Liu, B.; Wang, S.l.; Li, B.B.; Yang, T.; Li, H.; Liu, Y.; He, L. A Superelastic SMA Macroscopic Phenomenological Model Considering the Influence of Strain Amplitude and Strain Rate. Mater. Rep. 2020, 34, 14161-14167. (In Chinese)

24. Du, H.Y.; Han, Y.X.; Wang, L.X.; Melnik, R. A differential model for the hysteresis in magnetic shape memory alloys and its application of feedback linearization. Appl. Phys. A 2021, 127, 432. [CrossRef]

25. Lee, H.J.; Lee, J.J. Evaluation of the characteristics of a shape memory alloy spring actuator. Smart Mater. Struct. 2000, 9, 817-823. [CrossRef]

26. Ren, W.j.; Li, H.N.; Wang, L.Q. Superelastic shape memory alloy cyclic constitutive model based on neural network. Rare Met. Mater. Eng. 2012, 9, 243-246. (In Chinese)

27. Singh, M.P.; Moreschi, L.M. Optimal placement of dampers for passive response control. Earthq. Eng. Struct. Dyn. 2002, 31, 955-976. [CrossRef]

28. Amini, F.; Tavassoli, M.R. Optimal structural active control force, number and placement of controllers. Eng. Struct. 2005, 27, 1306-1316. [CrossRef] 
29. Guo, K.M.; Jiang, J. Optimal Locations of Dampers/Actuators in Vibration Control of a Truss-Cored Sandwich Plate. In Advances on Analysis and Control of Vibrations-Theory and Applications; de la Hoz, M.Z., Pozo, F., Eds.; IntechOpen: London, UK, 2012. [CrossRef]

30. Chen, G.S.; Bruno, R.J.; Salama, M. Optimal placement of active/passive members in truss structures using simulated annealing. AIAA J. 1991, 29, 1327-1334. [CrossRef]

31. Rao, S.S.; Pan, T.S. Venkayya V B Optimal Placement of Actuators in Actively Controlled Structures Using Genetic Algorithms. AIAA J. 1991, 29, 942-943. [CrossRef]

32. Mulay, N.; Shmerling, A. Analytical approach for the design and optimal allocation of shape memory alloy dampers in threedimensional nonlinear structures. Comput. Struct. 2021, 249, 106518. [CrossRef]

33. Pang, Y.T.; He, W.; Zhong, J. Risk-based design and optimization of shape memory alloy restrained sliding bearings for highway bridges under near-fault ground motions. Eng. Struct. 2021, 241, 112421. [CrossRef]

34. Zhan, M.; Wang, S.L.; Yang, T.; Liu, Y.; Yu, B.S. Optimum design and vibration control of a spatial structure with the hybrid semi-active control devices. Smart Struct. Syst. 2017, 19, 341-350. [CrossRef]

35. Fukuda1, T.; Takahata, M.; Kakeshita, T.; Saburi, T. Two-Way Shape Memory Properties of a Ti-51Ni Single Crystal Including Ti3Ni4 Precipitates of a Single Variant. Mater. Trans. 2001, 42, 323-328. [CrossRef]

36. Wang, W.; Fang, C.; Liu, J. Large size superelastic SMA bars: Heat treatment strategy, mechanical property and seismic application. Smart Mater. Struct. 2016, 25, 075001. [CrossRef]

37. Yun, C.B.; Yi, J.H.; Bahng, E.Y. Joint damage assessment of framed structures using a neural networks technique. Eng. Struct. 2001, 23, 425-435. [CrossRef]

38. Tsai, C.H.; Hsu, D.S. Diagnosis of Reinforced Concrete Structural Damage Base on Displacement Time History using the Back-Propagation Neural Network Technique. J. Comput. Civ. Eng. ASCE 2002, 16, 49-58. [CrossRef]

39. Liang, H.B.; Wei, Q.; Lu, D.Y.; Li, Z.L. Application of GA-BP neural network algorithm in killing well control system. Neural Comput. Appl. 2021, 33, 949-960. [CrossRef]

40. Yan, C.; Li, M.X.; Liu, W.; Qi, M. Improved adaptive genetic algorithm for the vehicle Insurance Fraud Identification Model based on a BP Neural Network. Theor. Comput. Sci. 2020, 817, 12-23. [CrossRef]

41. Li, J.; Chen, J.B. Dynamic response and reliability analysis of structures with uncertain parameters. Int. J. Numer. Methods Eng. 2005, 62, 289-315. [CrossRef]

42. Li, J.; Chen, J.B. The probability density evolution method for dynamic response analysis of non-linear stochastic structures. Int. J. Numer. Methods Eng. 2006, 65, 882-903. [CrossRef] 